\title{
Efficiency of the deposition mode ice nucleation on mineral dust particles
}

\author{
O. Möhler ${ }^{1}$, P. R. Field ${ }^{2, *}$, P. Connolly ${ }^{3}$, S. Benz ${ }^{1}$, H. Saathoff ${ }^{1}$, M. Schnaiter ${ }^{1}$, R. Wagner $^{1}$, R. Cotton ${ }^{2}$, M. Krämer ${ }^{4}$, \\ A. Mangold ${ }^{4, * *}$, and A. J. Heymsfield ${ }^{5}$ \\ ${ }^{1}$ Institute for Meteorology and Climate Research, Forschungszentrum Karlsruhe, Germany \\ ${ }^{2}$ Met Office, Exeter, UK \\ ${ }^{3}$ School of Earth, Atmospheric and Environmental Sciences, University of Manchester, Manchester, UK \\ ${ }^{4}$ Institut für Chemie und Dynamik der Geosphäre (ICG-I), Forschungszentrum Jülich, Germany \\ ${ }^{5}$ National Center for Atmospheric Research (NCAR), Boulder, CO, USA \\ *now at: National Center for Atmospheric Research (NCAR), Boulder, CO, USA \\ ** now at: Royal Meteorological Institute of Belgium, Brussels, Belgium
}

Received: 5 December 2005 - Published in Atmos. Chem. Phys. Discuss.: 23 February 2006

Revised: 29 May 2006 - Accepted: 19 June 2006 - Published: 21 July 2006

\begin{abstract}
The deposition mode ice nucleation efficiency of various dust aerosols was investigated at cirrus cloud temperatures between 196 and $223 \mathrm{~K}$ using the aerosol and cloud chamber facility AIDA (Aerosol Interaction and Dynamics in the Atmosphere). Arizona test dust (ATD) as a reference material and two dust samples from the Takla Makan desert in Asia (AD1) and the Sahara (SD2) were used for the experiments at simulated cloud conditions. The dust particle sizes were almost lognormally distributed with mode diameters between 0.3 and $0.5 \mu \mathrm{m}$ and geometric standard deviations between 1.6 and 1.9. Deposition ice nucleation was most efficient on ATD particles with ice-active particle fractions of about 0.6 and 0.8 at an ice saturation ratio $S_{i}<1.15$ and temperatures of 223 and $209 \mathrm{~K}$, respectively. No significant change of the ice nucleation efficiency was found in up to three subsequent cycles of ice activation and evaporation with the same ATD aerosol. This indicates that the phenomenon of preactivation does not apply to ATD particles. The desert dust samples SD2 and AD1 showed a significantly lower fraction of active deposition nuclei, about 0.25 at $223 \mathrm{~K}$ and $S_{i}<1.35$. For all samples the ice activated aerosol fraction could be approximated by an exponential equation as function of $S_{i}$. This indicates that deposition ice nucleation on mineral particles may not be treated in the same stochastic sense as homogeneous freezing. The suggested formulation of ice activation spectra may be used to calculate the formation rate of ice crystals in models, if the number concentration of dust particles is known. More experimental work is needed to quantify the variability of the
\end{abstract}

Correspondence to: O. Möhler

(ottmar.moehler@imk.fzk.de) ice activation spectra as function of the temperature and dust particle properties.

\section{Introduction}

Whether cirrus clouds have a net cooling or heating effect on climate depends, among other factors, on the number concentration, size, and habit of ice crystals and therefore on the cirrus formation mechanisms. It is known from numerous field and modelling studies that both homogeneous freezing of solution droplets and heterogeneous ice nucleation on the surface of insoluble aerosol particles contribute to the formation of ice crystals in cirrus clouds (Lynch et al., 2002). Trajectory model analysis of aircraft measurements (Ström et al., 2003) suggested that in parts of the polluted northern hemisphere, cirrus clouds are formed via the heterogeneous pathway, but that homogeneous ice nucleation is also involved (Haag et al., 2003; Seifert et al., 2003). Aircraft studies of wave clouds also indicated the role of heterogeneous ice nucleation (DeMott et al., 1998; Jensen et al., 1998; Field et al., 2001) and of mineral particles as ice nuclei (Targino et al., 2006).

Specific surface properties of the heterogeneous ice nuclei can markedly lower the ice supersaturation threshold for heterogeneous ice nucleation compared to homogeneous freezing (Pruppacher and Klett, 1997), thereby changing not only the frequency of occurrence but also the microphysical and optical properties of cirrus clouds (Kärcher and Lohmann, 2003; Haag et al., 2003; Lohmann et al., 2004). Heintzenberg et al. (1996) found desert dust particles

Published by Copernicus GmbH on behalf of the European Geosciences Union. 
probably originating from Saharan source regions to dominate the composition of non-volatile residuals of ice crystals in cirrus over the Alps. Chen et al. (1998) found enhanced number fractions of crustal particles, besides carbonaceous and metallic particles, in the population of ice nuclei measured over Northern America. More recently, the role of desert dust particles as ice nuclei was demonstrated by several aircraft-based studies of a Saharan dust plume event over Florida (DeMott et al., 2003; Sassen et al., 2003; Cziczo et al., 2004). Twohy and Poellot (2005) investigated the nature of ice residual particles in anvil cirrus at temperatures between $-21^{\circ} \mathrm{C}$ and $-56^{\circ} \mathrm{C}$. Crustal components were found, among other insoluble particles, especially at higher temperatures, whereas more soluble salt and sulphates were present at lower temperatures.

According to Vali (1985), the deposition mode ice nucleation is defined as the formation of ice from a supersaturated vapour environment directly onto a solid surface, whereas immersion freezing is induced by a nucleus suspended in a supercooled water droplet. It is also common to refer to ice nucleation of a nucleus immersed in a supercooled solution as immersion freezing. Mineral surfaces are known to effectively initiate ice formation both in the immersion freezing and deposition nucleation mode (Roberts and Hallett, 1968; Pruppacher and Klett, 1997; Zuberi et al., 2002; Bailey and Hallett, 2002). Hung et al. (2003) found that the heterogeneous ice nucleation rates of ammonium sulphate solution droplets with a mineral dust core depend, beside temperature and ice supersaturation, on the size of the immersed mineral particle. Archuleta et al. (2005) recently reported size-dependent ice nucleation efficiencies of aluminium oxide, alumina-silicate, and iron oxide particles as well as a desert dust sample from Asia.

In contrast to homogeneous freezing rates of solution droplets, which can be parameterised in numerical models mainly as function of the temperature, relative humidity, and aerosol parameters (Sassen and Dodd, 1988; Heymsfield and Miloshevich, 1993; Koop et al., 2000; Kärcher and Lohmann, 2002), microphysically based parameterisations for heterogeneous ice nucleation processes are more difficult to assess. Up to now, most models rely on empirical relations for the number concentrations of ice nuclei as functions of the temperature and/or ice saturation ratio (Fletcher, 1962; Meyers et al., 1992). Stochastic models have been developed to calculate the nucleation rates of supercooled water in contact with solid surfaces (Pruppacher and Klett, 1997). A new concept has been suggested to calculate heterogeneous freezing rates with modified stochastic nucleation rate equations as function of aerosol properties (Kärcher and Lohmann, 2003). In contrast to stochastic nucleation rates, concepts of instantaneous ice nucleation according to measured freezing nuclei spectra have been applied in models of heterogeneous ice nucleation above (Diehl and Wurzler, 2004) and below the homogeneous freezing temperature of pure water droplets (DeMott et al., 1998) .
The heterogeneous ice nucleation of various dust samples was comprehensively investigated in several series of experiments using the AIDA aerosol and cloud chamber facility. In this paper we describe the experimental methods and discuss results of experiments with dry mineral dust aerosols, mainly so-called Arizona test dust, at temperatures between $224 \mathrm{~K}$ and $196 \mathrm{~K}$. Results from similar experiments with desert dust samples from Africa and Asia are discussed in more detail in a companion paper by Field et al. (2006).

\section{Experimental methods}

\subsection{Description of AIDA cloud chamber}

Figure 1 schematically shows the setup and instrumentation of the aerosol and cloud chamber facility AIDA (Aerosol Interaction and Dynamics in the Atmosphere) of Forschungszentrum Karlsruhe, which was used for the ice nucleation studies. The facility can be operated as an expansion cloud chamber to investigate microphysical processes at simulated cloud conditions. Respective experimental methods have been described previously (Möhler et al., 2003, 2005a,b; Benz et al., 2005) and are only briefly summarised here. The facility mainly consists of a cylindrical aerosol vessel encased in a large, thermally insulated box and connected to a vacuum and air supply system. The aerosol vessel (4 m diameter, $84 \mathrm{~m}^{3}$ volume) can be evacuated to a pressure below $0.1 \mathrm{hPa}$ and filled with particle free synthetic air to start any experiment with clean conditions with an aerosol background concentration of less than $0.1 \mathrm{~cm}^{-3}$.

The interior of the thermally insulated box can be cooled by air ventilation to any temperature down to $183 \mathrm{~K}$. Cooling rates are limited by the air ventilation and cooling system to about $5 \mathrm{~K} \mathrm{~h}^{-1}$. Strong cooling or heating causes larger temperature gradients inside the box and is therefore achieved by automatic control during the night when no expansion experiments take place. The experiments discussed here are not performed during such strong temperature change conditions but by running the chamber at a constant temperature during each day of experiments. During constant temperature control, the temporal and spatial temperature variability is less than $\pm 0.3 \mathrm{~K}$ throughout the entire box. The interior of the aerosol vessel is additionally stirred with a mixing fan which is located in the bottom part of the aerosol vessel. Under stirred conditions, the temperature variability inside the aerosol vessel is less than $\pm 0.2 \mathrm{~K}$. Gas and wall temperatures are measured with an accuracy of $\pm 0.3 \mathrm{~K}$.

\subsection{Simulation of cloud expansion}

Before starting ice nucleation experiments, the cloud chamber is typically cooled to a temperature of about $268 \mathrm{~K}$ and filled with humidified air with a frost point temperature of at least $263 \mathrm{~K}$. During slow cooling, the excess water vapour forms a frost layer on the chamber walls. The frost layer 


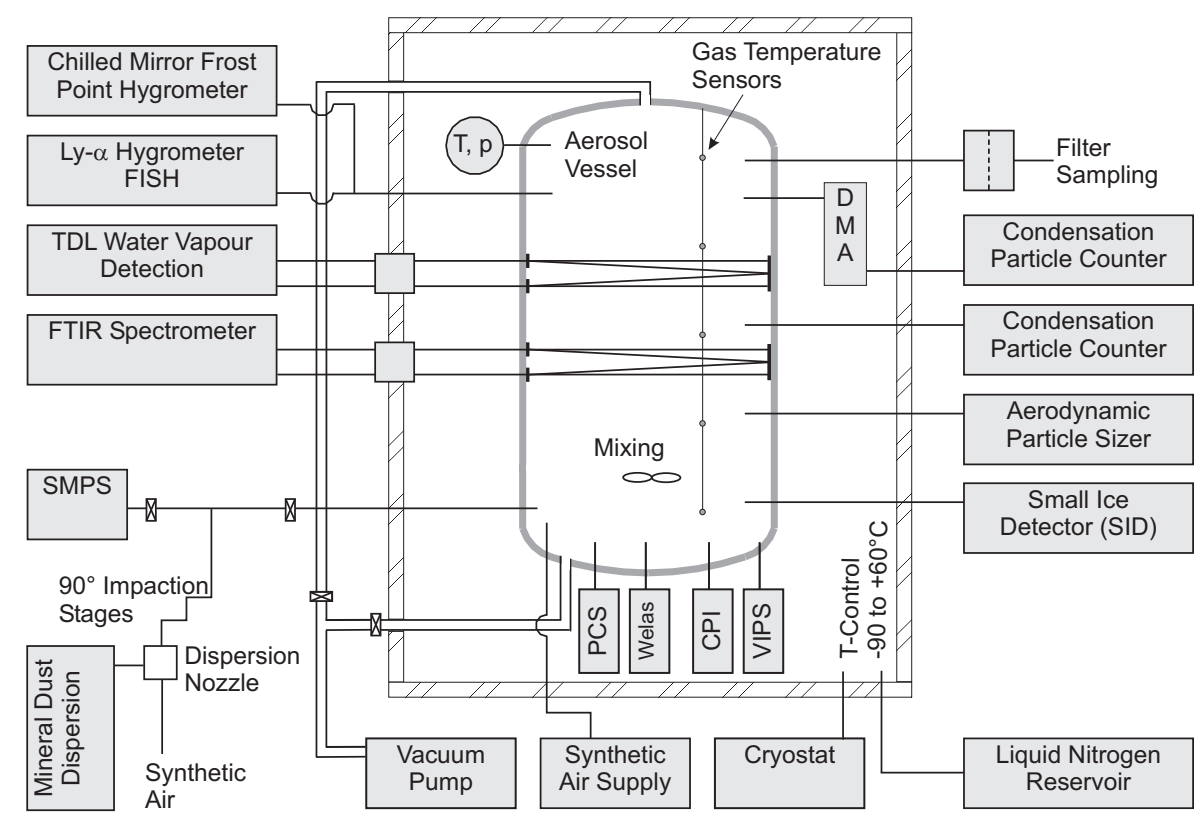

Fig. 1. Schematic of the AIDA (Aerosol Interaction and Dynamics in the Atmosphere) cloud simulation chamber with instrumentation for heterogeneous ice nucleation studies of mineral dust aerosols.

maintains almost ice saturated conditions at lower temperatures. After reaching conditions of uniform temperature (within $\pm 0.2 \mathrm{~K}$ ) and relative humidity (within $\pm 3 \%$ ) inside the aerosol vessel, the aerosol to be studied is added (see Sect. 2.3) and the first ice activation experiment is started. Ice supersaturated conditions are achieved by controlled pumping, typically from 1000 to $800 \mathrm{hPa}$. After pumping starts, the gas temperature $T_{g}$ drops almost adiabatically due to volume expansion. Because the wall temperature $T_{w}$ remains almost constant during expansion, there is a heat flux from the warmer walls to the volume, which increases with increasing $T_{w}-T_{g}$. Therefore, $T_{g}$ deviates from the adiabatic profile and approaches an almost constant steady state value after about 15 to $20 \mathrm{~min}$ of pumping at a constant rate of pressure change. The mixing fan maintains homogeneous temperature and humidity conditions inside the aerosol chamber. Even during strong pumping expansion and cooling, the spatial and short-term temperature variability is less than $\pm 0.3 \mathrm{~K}$, except for a few centimetre thick transition layer to the vessel walls.

With initially almost ice saturated conditions, ice saturation is exceeded shortly after pumping starts. The ice saturation ratio $S_{i}=e_{w} / e_{s, i}$ increases due to the fact that the water vapour saturation pressure with respect to ice, $e_{s, i}$, exponentially decreases with decreasing $T_{g}$, whereas the actual water vapour pressure, $e_{w}$, only linearly decreases with decreasing pressure during pumping. With the highest pumping speed, maximum initial cooling rates of about $4 \mathrm{~K} \mathrm{~min}^{-1}$ can be achieved in the AIDA chamber. This corresponds to the cooling rate of an adiabatically expanding air parcel as- cending in the upper troposphere at an updraft speed of about $6 \mathrm{~m} \mathrm{~s}^{-1}$. During the simulation runs, $S_{i}$ typically increases at a rate of about 0.1 to $0.5 \mathrm{~min}^{-1}$ (Möhler et al., 2005a).

\subsection{Origin, preparation, and characterisation of dust sam- ples}

Three mineral dust samples were used, namely two desert dust samples from Asia (AD1) and the Sahara (SD2) and socalled Arizona test dust (ATD). The sample AD1 which was provided by the University of Mainz, Germany, was collected from the ground in the easterly parts of the Takla Makan Desert in China, east of the Dalimu Basin between Kuerle and Ruoquiang. The Saharan dust SD2 is also a surface sample, which was collected about $50 \mathrm{~km}$ north of Cairo city, Egypt. Both desert samples were stored and transported in clean bottles to avoid contamination. The ATD sample was selected because it is available from Powder Technology Inc. (Minnesota, USA) as a reference material, which can be used in other labs for comparison of results and methods of ice nucleation. According to the manufacturer, ATD is produced by (1) grinding samples of sand from Arizona in a stainless steel ball mill, (2) separating the fine particle size fractions by elutriation in water, (3) drying the coarse material in an oven, (4) remilling and separating the dried sample into four distinct size classes, and (5) blending the four milling fractions to get a sample of the desired particle size distribution. We used a sample with a nominal $0-3 \mu \mathrm{m}$ particle diameter size range (batch No. 130300).

The elemental composition of each sample was analysed by X-ray fluorescence analysis (XRF, SRS 303AS, Bruker 
Table 1. Origin and properties of mineral dust samples.

\begin{tabular}{|c|c|c|c|}
\hline Sample & Arizona Test Dust & Asian Dust & Saharan Dust \\
\hline Key & ATD & AD1 & SD2 \\
\hline \multicolumn{4}{|c|}{ Elemental composition of the bulk samples (weight percentages from XRF analysis) } \\
\hline $\mathrm{Al}_{2} \mathrm{O}_{3}$ & 13.8 & 8.4 & 8.5 \\
\hline $\mathrm{CaO}$ & 4.3 & 11.5 & 22.9 \\
\hline $\mathrm{FeO}$ & 4.0 & 3.6 & 4.7 \\
\hline $\mathrm{K}_{2} \mathrm{O}$ & 3.8 & 2.0 & 1.2 \\
\hline $\mathrm{MgO}$ & 2.9 & 2.3 & 3.9 \\
\hline $\mathrm{Na}_{2} \mathrm{O}$ & 2.7 & 0.5 & 0.9 \\
\hline $\mathrm{P}_{2} \mathrm{O}_{5}$ & 0.2 & $<0.1$ & 0.2 \\
\hline $\mathrm{SiO}_{2}$ & 57.4 & 70.2 & 26.8 \\
\hline $\mathrm{TiO}_{2}$ & 0.6 & 0.8 & 0.8 \\
\hline Mass loss & 10.3 & 0.7 & 30.1 \\
\hline \multicolumn{4}{|c|}{ Lognormal size distribution parameters of the fine particle fraction added to the aerosol vessel } \\
\hline Number concentration $n_{a e}\left(\mathrm{~cm}^{-3}\right)$ & $222-645$ & 119 & $97-459$ \\
\hline Median diameter $(\mu \mathrm{m})$ & $0.35 \pm 0.05$ & $0.4 \pm 0.05$ & $0.35 \pm 0.05$ \\
\hline Geometric standard deviation & $1.65 \pm 0.05$ & $1.7 \pm 0.05$ & $1.85 \pm 0.05$ \\
\hline Surface area $s_{a e}$ for $n_{a e}=100 \mathrm{~cm}^{-3}\left(\mathrm{~cm}^{2} \mathrm{~cm}^{-3}\right)$ & $(6.4 \pm 2.4) \times 10^{-7}$ & $(8.8 \pm 3.0) \times 10^{-7}$ & $(8.4 \pm 3.6) \times 10^{-7}$ \\
\hline
\end{tabular}

AXS). Amounts of $200 \mathrm{mg}$ were taken from the ATD sample and from sieve fractions of AD1 and SD2 with particles smaller than $20 \mu \mathrm{m}$ in diameter. The $200 \mathrm{mg}$ dust samples were tempered for one hour at $1000^{\circ} \mathrm{C}$ prior to the analysis. The results listed in Table 1 are weight percentages of respective oxides. Silicon, aluminium, and calcium oxides are most abundant in all samples. ATD shows relatively large amounts of aluminium, AD1 of silicon, and SD2 of calcium oxides. The XRF analysis of ATD agrees with the composition given by the manufacturer except for the $\mathrm{SiO}_{2}$ mass fraction, which was about $5 \%$ below the range given by the manufacturer. In general, only limited information about the mineral composition can be derived from the bulk elemental analysis of dust samples. The presence of large amounts of $\mathrm{SiO}_{2}$ and $\mathrm{Al}_{2} \mathrm{O}_{3}$ indicate the presence of layer silicates. All dust samples used in the present studies showed larger fractions of $\mathrm{SiO}_{2}$ which indicates the presence of quartz particles. Minor abundance of kaolinite is also likely.

It should be noted that these are results of a bulk analysis with particles up to $20 \mu \mathrm{m}$ in diameter for the samples AD1 and SD2. The mineral composition will certainly change from particle to particle and probably also with particle diameter. In the latter case, the bulk analysis may not be representative of the aerosol used in our experiments because it is dominated by particles larger than $2 \mu \mathrm{m}$, while the aerosol sample used in the experiments was smaller than $2 \mu \mathrm{m}$. Aerosol particles smaller than $2 \mu \mathrm{m}$ in diameter were selected in the following way: First, the mechanically sieved fraction of particles smaller than $70 \mu \mathrm{m}$ was roughly dispersed with a rotating brush disperser (RGB 1000, Palas). The ATD sample was not sieved prior to dispersion because it contained only particles smaller than $3 \mu \mathrm{m}$ in diameter. Second, the finest particles were de-agglomerated in an aerosol dispersion nozzle. Third, particles larger than about $2 \mu \mathrm{m}$ in diameter were removed in a series of four $90^{\circ}$ inertial impactor stages with a $50 \%$ cut-off diameter of about $1.5 \mu \mathrm{m}$. Both, the brush disperser and the dispersion nozzle were operated with dry and particle-free synthetic air to avoid contamination of the dust aerosol with particles of unknown origin. The dispersion pressure of the nozzle was 1.5 bar. After passing the impactor stages the aerosol flow was directly added to the AIDA cloud chamber.

Figure 2 shows typical number size distributions of the three dust types ATD, AD1, and SD2 sampled from the AIDA aerosol chamber. The size distributions were measured with a scanning mobility particle sizer (SMPS, TSI) and an aerodynamic particle spectrometer (APS, TSI). A bulk density of $2.6 \mathrm{~g} \mathrm{~cm}^{-3}$ and a dynamic shape factor of 1.5 were used to convert the aerodynamic diameter measured with the APS into a mobility-equivalent diameter for comparison with the SMPS data. The measured size distributions have been approximated by a lognormal fit with a median diameter of $0.35,0.40$, and $0.35 \mu \mathrm{m}$ and a geometric standard deviation of 1.65, 1.70, and 1.85 for ATD, AD1, and SD2, respectively. At diameters below about $0.2 \mu \mathrm{m}$ the SMPS overestimates the number concentrations due to incomplete charge correction of multiply charged particles with diameters larger than $0.8 \mu \mathrm{m}$, the upper mobility size range limit of the SMPS system. 
The ranges of lognormal fit parameters for all mineral dust size distributions measured during the experiments discussed in this paper are given in Table 1. The respective surface areas $s_{a e}$ have been normalized to a number concentration $n_{a e}=100 \mathrm{~cm}^{-3}$. These surface areas will be used in Sect. 3.3 to estimate surface nucleation rates. Please note that we assumed spherical particle shapes to calculate $s_{a e}$. Electron micrographs showed the mineral particles to have irregular and partly aggregate-like structures. Therefore, the actual surface area of the dust aerosols may be somewhat higher than given in Table 1 . We were not able to quantify this structure dependent enhancement of surface area.

\subsection{Water vapour and ice saturation measurements}

The concentration of total water (gas and condensed phase) was measured with a fast scanning chilled mirror hygrometer (LX-373, MBW) and the Ly- $\alpha$ hygrometer FISH of Forschungszentrum Jülich (Zöger et al., 1999). Both instruments are located outside the cold box and take their sample flow through a stainless steel tube. All ice particles completely evaporate after entering the tube which is heated to $30^{\circ} \mathrm{C}$. The MBW chilled mirror instrument served as an accurate reference for the water vapour concentration if no ice particles were present in the aerosol vessel. Advantages of the FISH instrument are a higher sensitivity and time resolution. Both sampling instruments may underestimate the total water concentrations if large ice crystals are sampled at less than $100 \%$ efficiency into the horizontal sampling tube. This artifact does not affect the conclusions of this paper.

The water vapour pressure $e_{w}$ is directly measured in situ with a tunable diode laser (TDL) absorption spectrometer. The TDL system is based on a room temperature nearinfrared tunable diode laser at $1370 \pm 2 \mathrm{~nm}$ and an $82 \mathrm{~m}$ White multi-path cell (Ebert et al., 2005; Möhler et al., 2005a). The water vapour pressure $e_{w}$ is measured with a time resolution of $1 \mathrm{~s}$. Systematic errors, e.g. due to uncertainties of absorption line parameters taken from the literature, were eliminated by scaling the TDL data set to the chilled mirror data with a constant factor of up to 1.3 , depending on the water absorption line used for the TDL scans. The MBW chilled mirror instrument measures the frost point temperature with an accuracy of $\pm 0.1 \mathrm{~K}$. Therefore, the uncertainty of $e_{w}$ from TDL, after scaling, is only $\pm 1.3 \%$ at $220 \mathrm{~K}$ and $\pm 1.7 \%$ at $190 \mathrm{~K}$.

The mean gas temperature is measured with an accuracy of $\pm 0.3 \mathrm{~K}$, resulting in an uncertainty for $e_{s, i}$ of $\pm 3.9 \%$ at $220 \mathrm{~K}$ and $\pm 5.2 \%$ at $190 \mathrm{~K}$. Time series of the mean ice saturation ratio $S_{i}$ in the well-mixed chamber volume are obtained at a time resolution of $1 \mathrm{~s}$ from the ratio of $e_{w}$ and the ice saturation pressure $e_{s, i}$ as function of the mean gas temperature $T_{g}$. The latter is calculated as an average of measurements with four carefully calibrated thermocouples oriented along a vertical line located about $1 \mathrm{~m}$ from the center of the aerosol vessel. With the uncertainty of the water vapour data given

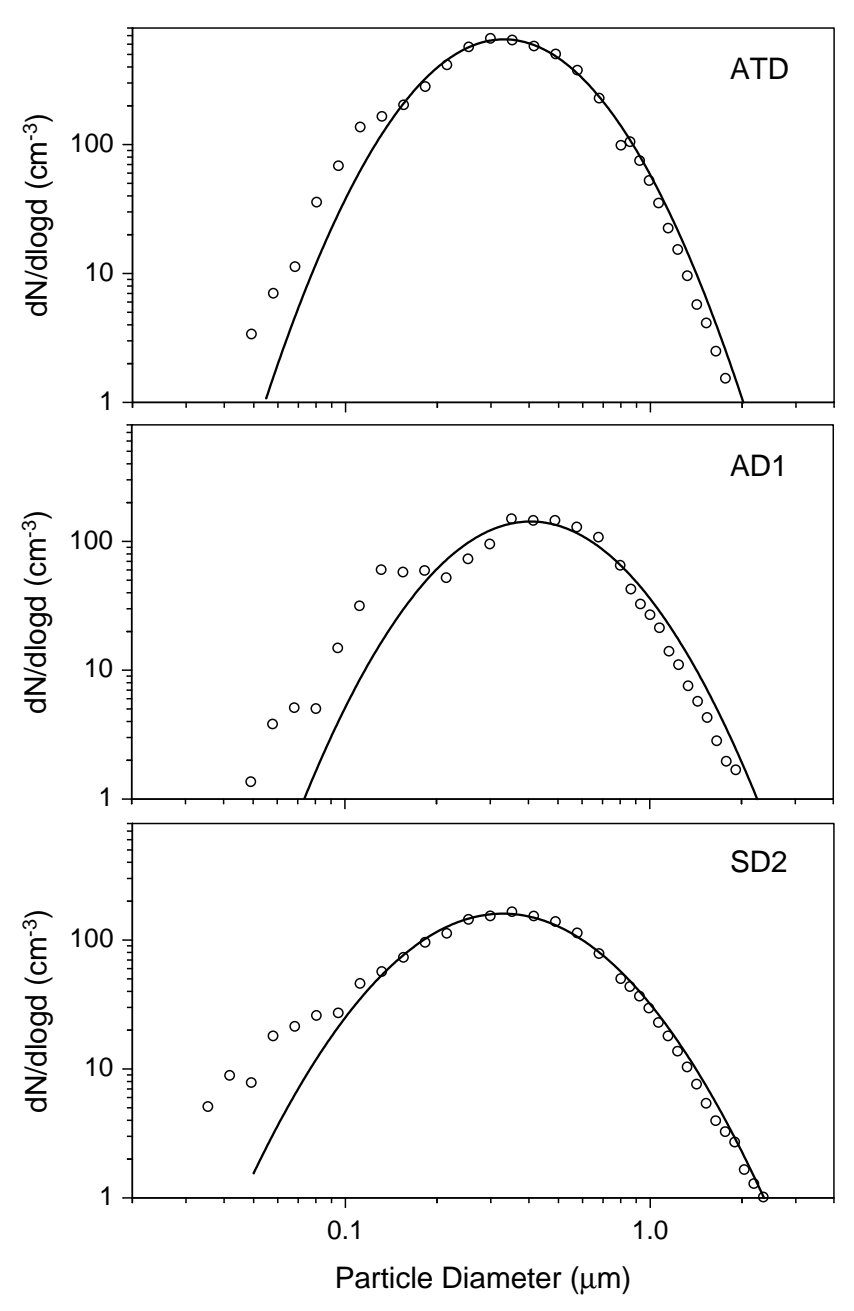

Fig. 2. Typical aerosol size distributions of Arizona test dust (ATD), Asian Dust (AD1), and Saharan dust (SD2) after dispersion and addition to the AIDA aerosol vessel.

above and the uncertainty of $\pm 0.3 \mathrm{~K}$ for $T_{g}$ we obtain an overall uncertainty for $S_{i}$ measurements of $\pm 4 \%$ at $220 \mathrm{~K}$ and $\pm 6 \%$ at $190 \mathrm{~K}$.

\subsection{Aerosol and ice particle measurements}

The total aerosol number concentration $n_{a e}$ was measured with a condensation particle counter (CPC3010, TSI), which has been modified and calibrated for sampling at reduced pressures between 1000 and $100 \mathrm{hPa}$ (Seifert et al., 2004). Aerosol particles with diameters up to about $2 \mu \mathrm{m}$ were sampled at $100 \%$ efficiency through a horizontally oriented stainless steel tube. Diffusional loss of particles in the sampling tube can be neglected because only a minor fraction of the particles is smaller than $100 \mathrm{~nm}$ in diameter (see Fig. 2). The sampling tube is about $2 \mathrm{~m}$ long and has an inner diameter of $4 \mathrm{~mm}$. About one half of the tube is located inside the aerosol vessel and the cold box. Therefore, small ice 
particles that form in the chamber during pumping expansion runs can pass this cold tube section and evaporate in the second part of the sampling tube at room temperature. The CPC then measures the sum of the interstitial aerosol and the residuals from smaller ice particles that do not settle out in the cold tube section. Because the size dependent ice particle loss in the sampling tube cannot quantitatively be determined, the contributions of aerosol particles and ice residuals to the reading of the CPC cannot quantitatively be ruled out if a significant fraction of the aerosol particles acted as ice nuclei.

During pumping expansion, the total particle concentration $n_{p}=n_{a e}+n_{\text {ice }}$, i.e. the sum of the interstitial aerosol and the ice particles or ice nuclei, can be calculated as $n_{p}=n_{a e}\left(t_{0}\right) \times\left(p / p\left(t_{0}\right)\right)$. This equation describes the pumping dilution of the initial aerosol concentration $n_{a e}\left(t_{0}\right)$ where $t_{0}$ denotes the time when pumping starts. It follows that the fraction $f_{i}$ of ice activated aerosol, which will be discussed in Sect. 3, is obtained from

$$
f_{i}=\frac{n_{\text {ice }}}{n_{p}}=\frac{n_{\text {ice }} p\left(t_{0}\right)}{n_{a e}\left(t_{0}\right) p}
$$

The number concentration $n_{\text {ice }}$ of ice particles is measured with two optical particle counters (PCS2000 and Welas, Palas GmbH, Germany) and the so-called small ice detector SID, which was developed by the University of Hertfordshire for aircraft-based cloud studies (Hirst et al., 2001). A technical description of the SID probe and its application to AIDA ice nucleation studies is given by Field et al. (2006). Most of the results discussed in the present paper rely on measurements with the PCS2000 instrument, hereafter termed OPCPCS. The OPC-PCS measures, at $90 \pm 12^{\circ}$ scattering angle, the intensity of white light scattered by single particles. The particle number concentration $n_{\mathrm{PCS}}$ can be calculated from the single particle count rate and the sample flow through the optical detection volume. The latter is calibrated with an aerosol of known number concentration.

The OPC-PCS is not only sensitive to ice particles but also to dust aerosol particles, depending on their size and refractive index. Dust particles have refractive indices typically larger than 1.5 and are therefore detected with the OPC-PCS if larger than about $0.5 \mu \mathrm{m}$ in diameter. According to the aerosol size distributions shown in Fig. 2, the OPC-PCS detects a smaller amount of the total dust aerosol. Ice particles have a relatively low refractive index of 1.32 and are therefore detected only if larger than about $0.8 \mu \mathrm{m}$ in diameter. Because there is an overlapping size range for aerosol and ice particles detected with the OPC-PCS, the ice particle number concentration is not directly obtained from these measurements. During an expansion experiment, it can be calculated from the relative increase of the OPC-PCS number concentration which is caused by the growth of ice crystals to sizes above the detection threshold. Hygroscopic growth of dust particles can be neglected under the conditions of the experiments discussed here. Ion chromatographic analysis showed that the soluble mass fraction of the dust samples ATD, AD1 and SD2 was below 1\%. Furthermore, experiments at room temperature (Gustafsson et al., 2005) revealed the hygroscopic growth factors of ATD particles to be less than 1.05 for relative humidities up to $75 \%$. From this we conclude that any increase of $n_{\text {PCS }}$ can be attributed to pristine ice crystals with $d>0.8 \mu \mathrm{m}$. Taking into account pumping dilution, the ice number concentration is estimated as

$n_{\text {ice }} \approx n_{\mathrm{PCS}}-n_{\mathrm{PCS}}\left(t_{0}\right) \frac{p}{p\left(t_{0}\right)}$

In addition, the total number concentration $n_{\mathrm{PCS}}$ gives an upper estimate for $n_{\text {ice }}$. The ice particle detection is delayed by the growth time of pristine deposition ice germs to ice crystals of a detectable size $d>0.8 \mu \mathrm{m}$. During this growth, the ice particles pass the transition regime from kinetically controlled growth to diffusion growth. A molecular accommodation coefficient of 0.5 was used to calculate the growth rate in the kinetic regime. For the transition regime to diffusion growth we used a formulation suggested by Dahneke (1983). Latent heat terms are not included because they have only a minor impact on the growth rate under the conditions of our experiments. Respective growth times are $4 \mathrm{~s}$ at $223 \mathrm{~K}$, $8 \mathrm{~s}$ at $210 \mathrm{~K}$, and $50 \mathrm{~s}$ at $196 \mathrm{~K}$. This delay of ice particle detection with the OPC is considered in the analysis of the ice activation spectra discussed in Sect. 3.

Ice particle number concentrations were also retrieved from Fourier Transform Infrared (FTIR) extinction spectra as described by Mangold et al. (2005). The extinction spectra were measured in situ with a White-type multiple reflection cell with a horizontal optical path of up to $254.3 \mathrm{~m}$ (Wagner et al., 2005). Spectra are recorded with a FTIR spectrometer (IFS 66v, Bruker) in the wave number range 800 to $6000 \mathrm{~cm}^{-1}$, at a resolution of $4 \mathrm{~cm}^{-1}$, and at a rate of $3 \mathrm{spec}-$ tra per minute. T-matrix calculations using the code for randomly oriented circular cylinders (Mishchenko and Travis, 1998) were performed to fit the measured extinction spectra of the ice particles. In our previous study (Mangold et al., 2005) the aspherical ice particles were represented in the calculations by cylinders with a fixed aspect ratio $D / L=0.7$, where $D$ is the diameter and $L$ the length of the cylinder. In the present work, aspect ratios ranging from 0.5 to 3.0 were employed to examine more thoroughly the effect of particle asphericity on the retrieval results. The deduced ice particle number concentrations and ice particle fractions discussed in Sect. 3 together with the OPC data represent averaged fit results over the specified range of aspect ratios. The details of this approach, as well as a systematic comparison of the ice particle number concentrations measured with the OPCPCS, OPC-Welas, and SID instruments and those retrieved from the FTIR extinction spectra, are discussed in more detail by Wagner et al. (2006).

In this paper, we discuss ice nucleation results from three distinct series of ice nucleation experiments hereafter termed IN02, IN03, and IN04 (see Sect. 2.6 and Table 2). FTIR 


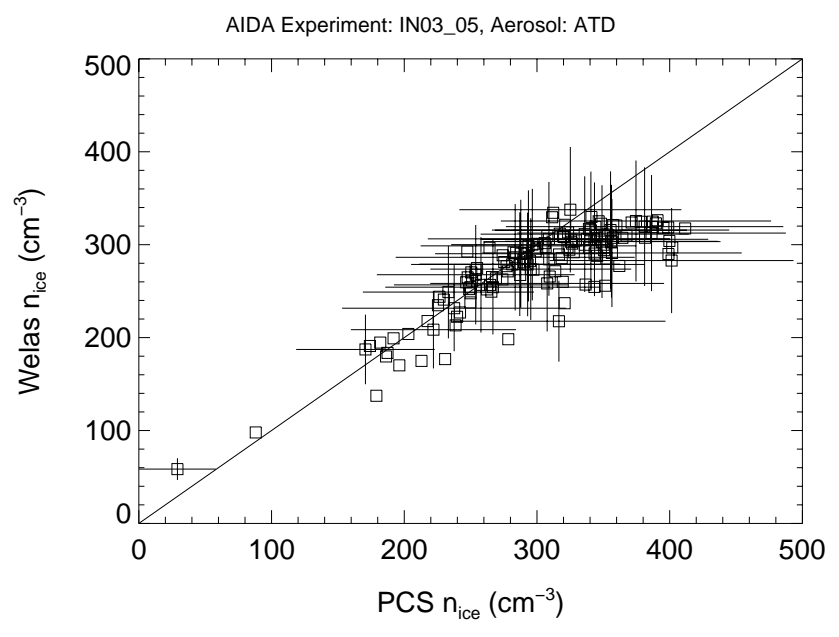

Fig. 3. Comparison of ice particle concentrations measured with the optical particle counters Welas and PCS2000.

measurements were performed during all experiments. The OPC-PCS was available only during INO2 and IN03. The optical particle counter Welas (OPC-Welas), an improved version of the OPC-PCS, was used during IN03 and IN04. The optical setup of the OPC-Welas is similar to the OPC-PCS. A major advantage of the OPC-Welas is a separate optics block, which is connected with optical fibres to the lamp and photomultiplier unit. The small optical sensor can be operated at the same temperature as the aerosol chamber without additional heaters and with only a very short sampling tube. Therefore the risk of ice particle sampling losses and evaporation is markedly reduced. Only during INO3, both OPCs were available for simultaneous measurements and intercomparison. Both probes were mounted below the cloud chamber to vertical sampling tubes of about $1 \mathrm{~m}$ length and $8 \mathrm{~mm}$ inner diameter. From the OPC-Welas, data sets of $n_{\text {ice }}$ were obtained in the same way as for the OPC-PCS sensor (see Eq. 2). The OPC-Welas is also sensitive to ice particles with $d>0.8 \mu \mathrm{m}$. Figure 3 shows, for experiment IN03_5, a typical scatter plot of the OPC-PCS and the OPC-Welas data set. The error bars include both counting errors and an estimated uncertainty of $\pm 10 \%$ for the conversion of the count rate into a number concentation. The major contribution to the latter comes from the uncertainty of the flow velocity through the optical detection volume. The counting efficiency was independently determined by comparison to measurements with a condensation particle counter. The data set in Fig. 3 indicates good agreement between both OPCs within the estimated range of uncertainty. In addition to the OPC-Welas the small ice detector SID was available during IN04 for measurements of the ice particle number concentration. The uncertainty of SID ice particle concentrations is about $\pm 20 \%$. As shown in Fig. 4 there is also good agreement between ice particle number concentrations measured with the OPCWelas and the SID probe.

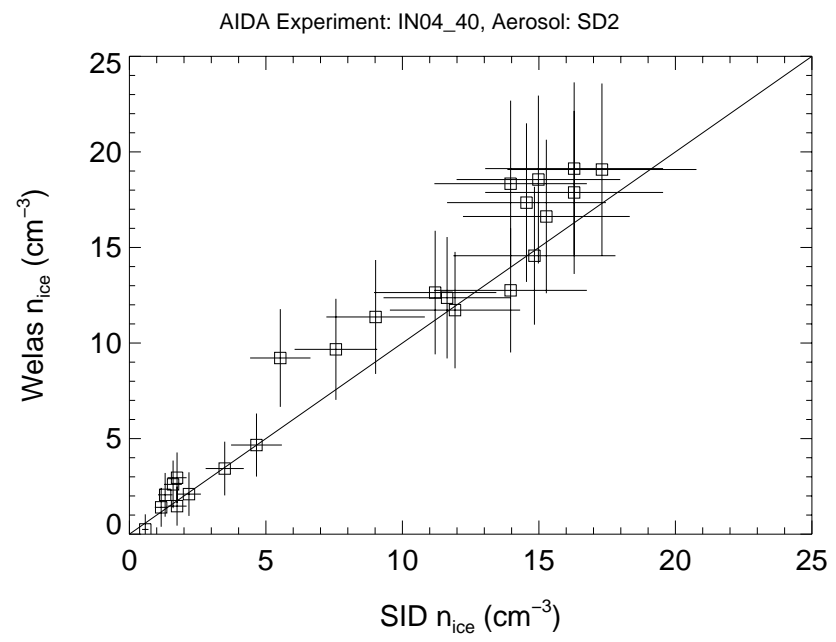

Fig. 4. Comparison of ice particle concentrations measured with the optical particle counter Welas and the small ice detector SID.

\subsection{Experimental parameters}

As explained in Sect. 2.2 an AIDA cloud expansion run is started at homogeneous temperature and pressure conditions. The initial pressure $p$, gas temperature $T_{g}$, and aerosol number concentration $n_{a e}$ are listed in Table 2 for all runs discussed in this paper. The experiments were carried out in three series of AIDA ice nucleation studies (IN02, IN03, and IN04). All runs were started at an initial pressure $p\left(t_{0}\right)$ close to $1000 \mathrm{hPa}$ and an ice saturation ratio of about 0.95 (not shown in the table). Initial temperatures $T_{g}\left(t_{0}\right)$ ranged from 196.4 to $223.5 \mathrm{~K}$ and the aerosol number concentrations from about 100 to $650 \mathrm{~cm}^{-3}$. In this paper we mainly focus on the deposition ice nucleation efficiency of the freshly dispersed mineral dust samples ATD, AD1, and SD2. Two series of experiments with ATD and initial temperatures of $223 \mathrm{~K}$ (IN02_147 to IN02_149) and 210 K (IN03_05 to IN03_07) investigated the ice nucleation of the same dust aerosol in subsequent ice activation and evaporation cycles. The ice nucleation efficiency of freshly dispersed Saharan dust SD2 was investigated in the same temperature range as ATD. Only one experiment with AD1 has been carried out with an initial $T_{g}$ of $222 \mathrm{~K}$. The characteristics of ice nucleation on the desert dust samples AD1 and SD2 in subsequent activation and evaporation cycles are discussed in more detail by Field et al. (2006).

Also listed in Table 2 are parameters of an exponential fit to the ice activation spectra, which will be discussed in Sect. 3.2 in terms of the fraction $f_{i}$ of ice activated aerosol particles as function of $S_{i}$. The threshold data for $f_{i}>0.08$ and the $f_{i}$ measured at the peak ice saturation ratio will also be discussed in Sect. 3.2. 
Table 2. Parameters of AIDA experiments and measured nucleation rates $J$.

\begin{tabular}{|c|c|c|c|c|c|c|c|c|c|c|c|c|c|c|}
\hline \multicolumn{5}{|c|}{ Initial experimental parameters } & \multicolumn{2}{|c|}{ Fit parameter } & \multicolumn{6}{|c|}{ Data for $f_{i}=0.08$} & \multicolumn{2}{|c|}{ Peak $S_{i}$ data } \\
\hline Experiment & Sample & $\begin{array}{c}p \\
\mathrm{hPa}\end{array}$ & $\begin{array}{l}T_{g} \\
\mathrm{~K}\end{array}$ & $\begin{array}{c}n_{a e} \\
\mathrm{~cm}^{-3}\end{array}$ & $S_{0}$ & $a$ & $\begin{array}{c}p \\
\mathrm{hPa}\end{array}$ & $\begin{array}{l}T \\
\mathrm{~K}\end{array}$ & $S_{i}$ & $\begin{array}{c}d S_{i} / d t \\
\mathrm{~s}^{-1}\end{array}$ & $d f_{i} / d S_{i}$ & $\begin{array}{c}J_{S} \\
\mathrm{~cm}^{-2} \mathrm{~s}^{-1}\end{array}$ & $S_{\max }$ & $f_{\max }$ \\
\hline IN02_147 & ATD & 1003.8 & 223.3 & 645 & 1.03 & 6.3 & 990.9 & 222.6 & 1.04 & 0.0040 & 6.8 & $4 \times 10^{6}$ & 1.09 & 0.60 \\
\hline IN02_148 & ATD & 1003.9 & 223.4 & 429 & 1.04 & 3.3 & 990.0 & 222.6 & 1.07 & 0.0049 & 3.6 & $3 \times 10^{6}$ & 1.15 & 0.55 \\
\hline IN02_149 & ATD & 1003.9 & 223.5 & 267 & 1.01 & 4.5 & 991.9 & 222.8 & 1.03 & 0.0035 & 4.9 & $3 \times 10^{6}$ & 1.14 & 0.57 \\
\hline IN03_05 & ATD & 1004.6 & 210.8 & 424 & 1.06 & 5.8 & 970.9 & 208.9 & 1.07 & 0.0074 & 6.3 & $7 \times 10^{6}$ & 1.16 & 0.88 \\
\hline IN03_06 & ATD & 1004.5 & 210.6 & 310 & 1.08 & 13.2 & 967.8 & 208.7 & 1.09 & 0.0026 & 14.2 & $6 \times 10^{6}$ & 1.12 & 0.81 \\
\hline IN03_07 & ATD & 1004.5 & 210.5 & 222 & 1.07 & 8.6 & 966.6 & 208.5 & 1.08 & 0.0022 & 9.3 & $3 \times 10^{6}$ & 1.13 & 0.79 \\
\hline IN03_21 & ATD & 1013.1 & 196.4 & 361 & 1.1 & - & - & - & - & - & - & - & 1.42 & 0.9 \\
\hline IN04_40 & SD2 & 991.7 & 224.0 & 107 & 1.17 & 0.43 & 933.8 & 220.8 & 1.35 & 0.0037 & 0.46 & $2 \times 10^{5}$ & 1.45 & 0.24 \\
\hline IN04_44 & SD2 & 990.45 & 213.1 & 97 & 1.00 & 1.7 & 979.6 & 212.6 & 1.04 & 0.0046 & 1.8 & $1 \times 10^{6}$ & 1.24 & 0.51 \\
\hline IN03_11 & SD2 & 999.8 & 210.0 & 459 & 1.05 & 3.0 & 969.0 & 208.3 & 1.08 & 0.0049 & 3.3 & $2 \times 10^{6}$ & 1.14 & 0.37 \\
\hline IN03_16 & SD2 & 1006.4 & 197.0 & 322 & 1.02 & - & - & - & - & - & - & - & 1.44 & 0.81 \\
\hline IN04_26 & $\mathrm{AD} 1$ & 1005.7 & 222.2 & 119 & 1.21 & 0.87 & 956.3 & 219.5 & 1.30 & 0.0046 & 0.94 & $5 \times 10^{5}$ & 1.41 & 0.26 \\
\hline
\end{tabular}

\section{Results and discussion}

\subsection{Time series}

Figures 5 and 6 show time series of data sets from the expansion runs IN02_147 and IN03_05 with initial temperatures of $223.3 \mathrm{~K}$ and $210.8 \mathrm{~K}$, respectively. Similar data sets have been obtained for all experiments listed in Table 2 . The time is given in seconds relative to the time $t_{0}$ when the pumping started. Only the first $200 \mathrm{~s}$ of pumping to $800 \mathrm{hPa}$ are considered here. The pressure drop due to pumping is shown in panel 1. Panel 2 depicts the almost constant wall temperature $T_{w}$ (dashed line) and the gas temperature $T_{g}$ (solid line), which decreases due to expansion cooling during pumping. As mentioned above, the cooling rate is greatest when the pumping starts and slightly decreases with time due to an increasing heat flux from the warmer vessel walls.

With cooling of the well-mixed chamber volume, the ice saturation (panel 3) calculated as the ratio of the actual water vapour pressure from the TDL instrument and the ice saturation pressure with respect to $T_{g}$ starts to increase from an initial value of about 0.95 during experiment IN02_147 and 0.82 during experiment IN03_05. The lower initial value during experiment IN03_05 is due to the fact that the wall ice layer was almost consumed from previous ice nucleation runs. The ice layer is diminished run by run because the evacuated aerosol vessel is replenished with dry synthetic air. Nevertheless, the initial relative humidity was high enough to exceed the threshold humidity for ice nucleation after short time of pumping expansion. During both experiments the TDL spectrometer accurately measured the water vapour pressure from the start of pumping until about $50 \mathrm{~s}$ after the maximum ice saturation ratio was reached. Thereafter, the data are omitted in the figures because the noise on the TDL signal increased by a factor of 5 to 10 due to mechanical vibrations from the pumping system. The dashed line in panel 3 shows the ice saturation ratio calculated from the total water concentration, which was measured with the Ly- $\alpha$ hygrometer FISH during experiment IN02_147 and the chilled-mirror hygrometer MBW during experiment IN03_05. There is good agreement between the total and gasphase water data until the onset of ice nucleation. Later on, the increasing difference between both data sets indicates the increasing water content of the growing ice particles.

Panel 4 of Figs. 5 and 6 shows measured number concentrations of aerosol $\left(n_{a e}\right)$ and ice particles $\left(n_{\text {ice }}\right)$. The solid line depicts $n_{a e}$ directly measured with the CPC 3010 . The dashed line indicates the total particle number concentration calculated from the initial aerosol concentration assuming constant mixing ratio of particles during pumping. As explained in Sect. 2.5, the difference between the solid and dashed lines indicates partial loss of larger ice particles by sedimentation in the sampling tube of the CPC3010 instrument. This loss is only small in the examples shown here but can be much larger in experiments at higher temperatures and low ice nuclei concentrations when the ice particles grow to larger sizes. The number concentration of ice particles was calculated with Eq. (2) from OPC-PCS measurements (stars in panel 4) and retrieved from FTIR extinction spectra (solid squares). The OPC-PCS time series have been shifted by 4 and $8 \mathrm{~s}$ in Figs. 5 and 6, respectively, which accounts for the characteristic time of ice crystal growth into the detection range of the OPC-PCS instrument (see Sect. 2.5).

In general, the OPC-PCS ice number concentrations are in good agreement with those retrieved from the FTIR extinction spectra. After the onset of ice nucleation the number of ice crystals increased until $S_{i}$ reached its peak value $S_{\max }$. This maximum value of $S_{i}$ (see Table 2) mainly depends on the rate of ice particle formation, the growth rate of the ice crystals and the cooling rate. $S_{\max }$ of only 1.09 and 1.16 are 


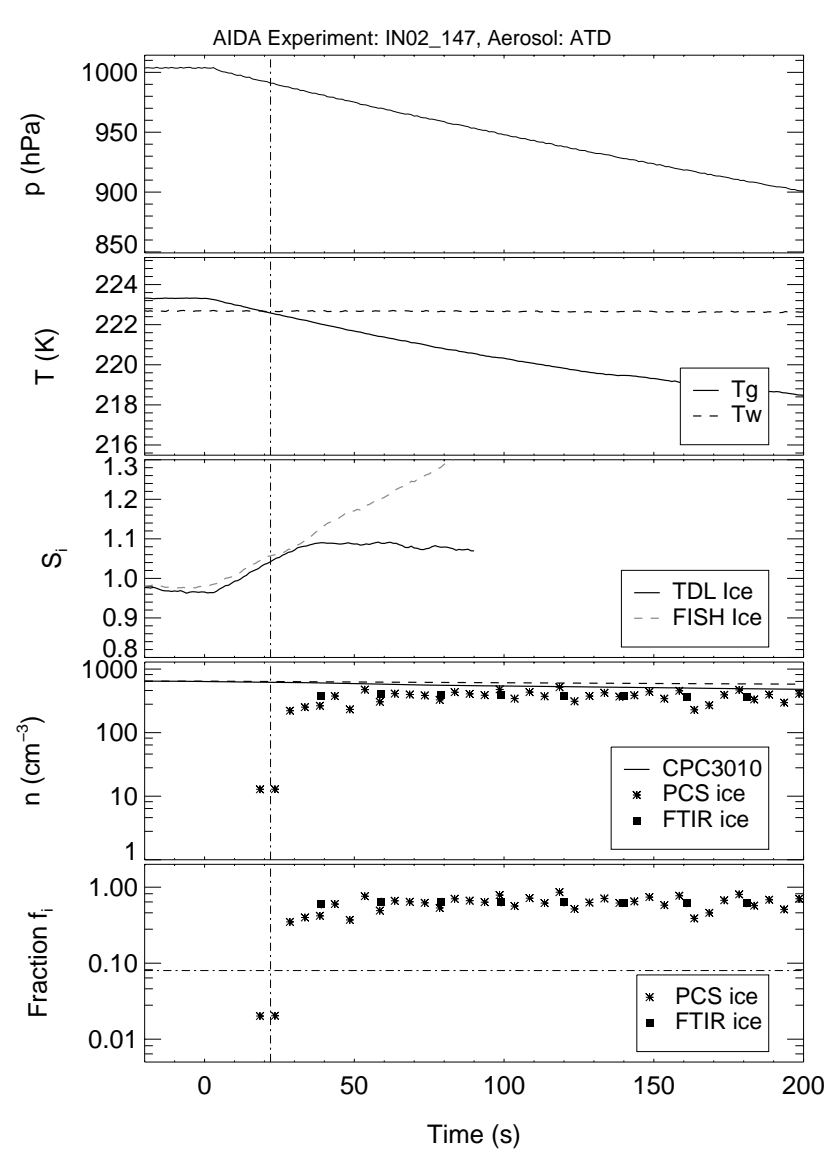

Fig. 5. Time series from experiment IN02_147 with ATD at 223.3 K. Panel 1 (from top): pressure; panel 2: mean gas temperature; panel 3: ice saturation ratio; panel 4: number concentration of aerosol and ice particles (see text); panel 5: ice particle fraction to total aerosol. The vertical dashed-dotted line marks the time when the ice-activated fraction $f_{i}$ exceeded a value of 0.08 .

reached in experiments IN02_147 and IN03_05, respectively. In all experiments discussed here, the formation of new ice particles was mainly observed in relatively short time periods when $S_{i}$ increased from a threshold value for onset of ice nucleation close to 1 to $S_{\max }$. Formation of new ice crystals almost instantly stopped after $S_{\max }$ was reached. In the further course of an experiment, $S_{i}$ stayed almost constant or only slightly decreased without any further formation of new ice crystals. The formation rate of ice crystals by deposition nucleation on the surface of dust particles is mainly a function of $S_{i}$ at a given temperature. This indicates that time is only a secondary effect and that at least the deposition mode nucleation rate may not be described in the same stochastic manner as homogeneous freezing as already pointed out in previous work (DeMott et al., 1998).

The fraction $f_{i}$ of ice particles to the total aerosol particle concentration (see Eq. 1) is shown in panel 5 of Figs. 5 and 6. Similar to the total ice particle concentration, $f_{i}$ steadily increases after the onset of ice nucleation and stays almost con-

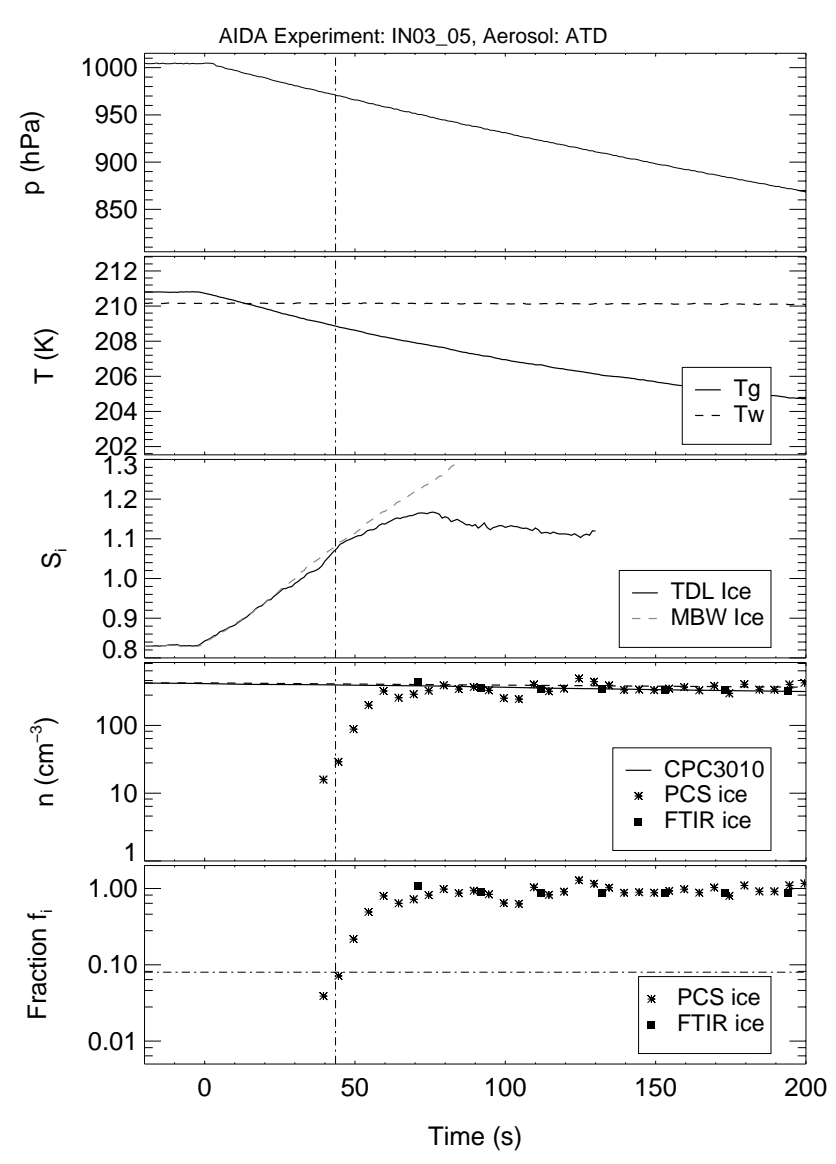

Fig. 6. Same as Fig. 5, but for experiment number IN03_05 with ATD at $210.8 \mathrm{~K}$.

stant after the time $t_{\max }$ when $S_{\max }$ was reached. The relation between $f_{i}$ and $S_{i}$ will be discussed in detail in Sect. 3.2. In the following paragraphs we discuss the ice particle fraction $f_{\max }$ measured at $t_{\max }$ which gives a first idea of the ice nucleation efficiency of the different dust samples as function of the ice saturation ratio and temperature (see also Mangold et al., 2005). We do not attempt here to quantitatively describe $S_{\max }$ as function of the cooling rate, the formation rate of ice crystals, and the dynamic partitioning of water vapour between the gaseous and condensed phases. This will be done in a process modelling study which is in preparation. However, it is obvious that $S_{\max }$ tends to be higher for (1) faster cooling rates, (2) less efficient ice formation (smaller ice surface for uptake of water vapour) or lower aerosol concentration, and (3) lower temperature (slower crystal growth rates). Table 2 shows $S_{\max }$ of all experiments to range between 1.09 and 1.45 with respective $f_{\max }$ between 0.26 and 0.88 . All $f_{\max }$ data was obtained by linear interpolation of the FTIR $f_{i}$ data points to $t_{\max }$. The data show that significant number fractions of the dust particles are active deposition ice nuclei at very low ice supersaturations. 


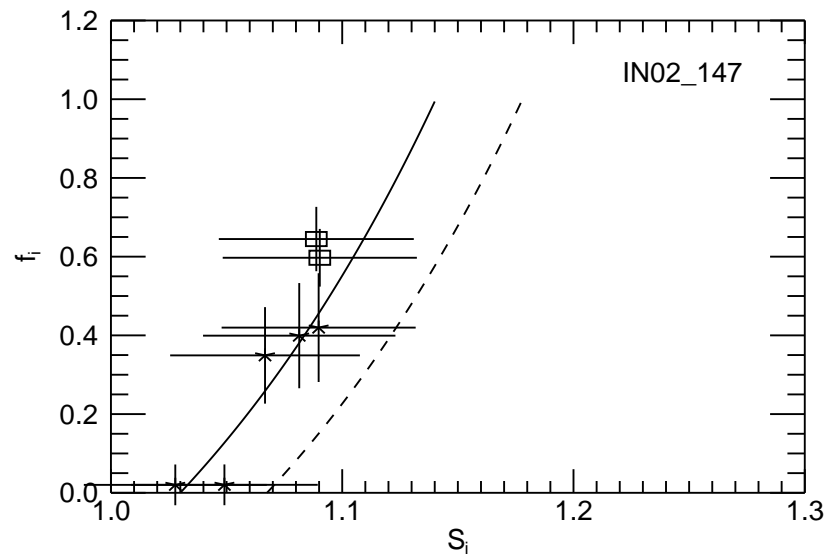

Fig. 7. Fraction $f_{i}$ of ice activated aerosol particles as function of the ice saturation ratio $S_{i}$ measured during experiment IN02_147 with ATD at 222.6K. $S_{i}$ was calculated as function of the mean gas temperature $T_{g}$ (solid line) and $T_{g}-0.3 \mathrm{~K}$ (dashed line).

In three subsequent expansion runs with the same ATD aerosol starting at $T \approx 223 \mathrm{~K}$ (runs IN02_147 to IN02_149) about $60 \%$ of the dust particles acted as deposition ice nuclei at $S_{i}<1.15$. At $T \approx 210 \mathrm{~K}$ (runs IN03_05 to IN03_07) a somewhat higher ATD aerosol number fraction of about $80 \%$ is activated in the same range of supersaturation. Note that in both series the number concentrations decreased from run to run both by dilution during pumping and refilling with particle free synthetic air and by partial deposition of ice particles. The dust particles were exposed to $S_{i} \approx 0.5$ for about 20 min when the aerosol chamber was replenished with synthetic air in between two pumping expansion runs. Furthermore, different pumping speeds were applied in the different runs which is reflected by the parameter $d S_{i} / d t$ in Table 2. Changes of both the aerosol number concentration and $d S_{i} / d t$ had no significant effect on the peak $S_{i}$ and $f_{i}$ data. Only during IN03_21 with ATD at the lowest temperature of $196 \mathrm{~K}$ the maximum $S_{i}$ was higher, mainly resulting from the high pumping speed during this run combined with slower ice particle growth rate at the low temperature and therefore a slower depletion rate by uptake of water vapour to the ice surface. It is likely that most of the ice crystals already formed at saturation ratios below the peak value of 1.41, but could not be detected earlier because of the dalayed growth of the ice crystals into the detection range of the OPC-PCS and the FTIR retrieval (see Sect. 2.5). No reliable correction for the growth time delay was possible at temperatures around $196 \mathrm{~K}$.

During two runs with SD2 and AD1 and initial temperatures above $220 \mathrm{~K}, f_{i}$ was limited to 0.24 for SD2 and 0.26 for AD1 with $S_{\max }$ of 1.45 and 1.41, respectively. Two more runs with SD2 at initial temperatures of $213.1 \mathrm{~K}$ and $210.0 \mathrm{~K}$ show significantly lower $S_{\max }$ and higher $f_{\max }$. This indicates a strong temperature dependence with higher ice nu-

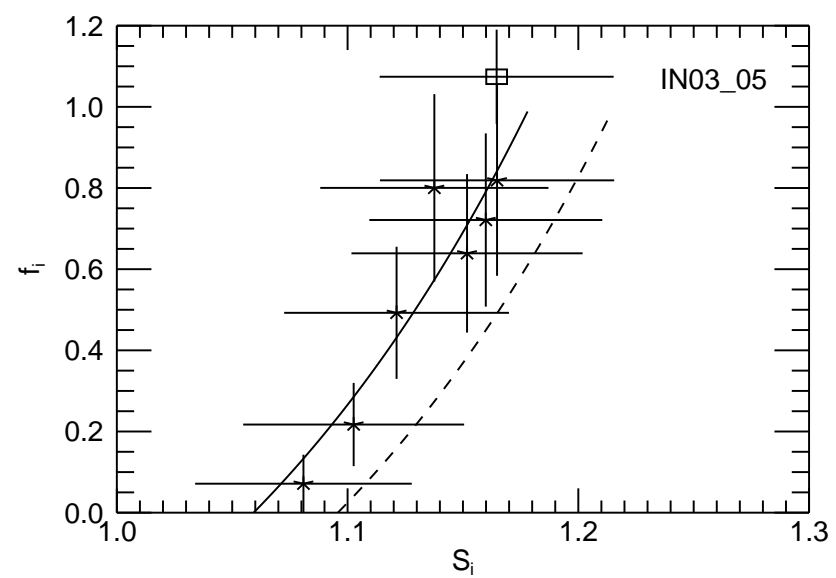

Fig. 8. Fraction $f_{i}$ of ice activated aerosol particles as function of the ice saturation ratio $S_{i}$ measured during experiment IN03_05 with ATD at $210.8 \mathrm{~K} S_{i}$ was calculated as function of the mean gas temperature $T_{g}$ (solid line) and $T_{g}-0.3 \mathrm{~K}$ (dashed line).

cleation efficiency at lower temperature. At the lowest temperature run with SD2 we can, for the same reasons as discussed above for the runs with ATD, assume that the value of 1.44 for $S_{\max }$ is only an upper limit for $f_{i}$ to reach a value of 0.81 . Unfortunately, no runs with AD1 are available so far at $T<220 \mathrm{~K}$.

\subsection{Ice activation spectra}

In this section we discuss the efficiency of the different mineral aerosol particles as deposition ice nuclei in terms of the ice activated number fraction $f_{i}$ as function of the increasing ice saturation ratio $S_{i}$. Two examples for this relation are plotted in Figs. 7 and 8 for experiments IN02_147 and IN03_05, respectively. The figures depict only data between $t_{0}$, the start of pumping, and $t_{\max }$, the time when the maximum $S_{i}$ was reached. $f_{i}$ was obtained from the OPC-PCS data set at a time resolution of $5 \mathrm{~s}$ (stars). Only few data points of $f_{i}$ were obtained from the FTIR spectra before $t_{\max }$ (open squares). The error bars for $S_{i}$ include uncertainties of the measured water vapour pressures and ice saturation pressures as discussed in Sect. 2.4. An additional systematic uncertainty of the measured ice nucleation onset may arise from the fact that the ice nucleation is initiated by a temperature somewhat lower than the mean temperature (it is unlikely that the ice formation is initiated by the warmer fraction of the chamber volume). The temporal and spatial variability around the mean temperature is typically less than $\pm 0.3 \mathrm{~K}$. If the observed ice formation would be initiated at $T_{g}-0.3 \mathrm{~K}$ instead of $T_{g}, S_{i}\left(T_{g}\right)$ discussed in the present paper would systematically underestimate the ice nucleation thresholds by about $4 \%$ at $220 \mathrm{~K}$ and $5 \%$ at $190 \mathrm{~K}$. This is indicated by the dashed line in Figs. 7 and 8. 
As already indicated in the discussion of the time series and maximum values of $f_{i}$ and $S_{i}$ in Sect. 3.1, the number fraction of mineral dust particles acting as deposition ice nuclei is mainly determined, at a given initial temperature of AIDA expansion experiments, by the increasing ice saturation ratio. Meyers et al. (1992) fitted an exponential function to atmospheric ice nuclei measurements at temperatures between 266 and $253 \mathrm{~K}$, which is used in cloud models to calculate the number of ice particles as function of the ice saturation ratio. Based on our experimental results, we suggest a similar exponential equation to parameterise the fraction of mineral particles acting as deposition nuclei as function of $S_{i}-S_{0}$. It is assumed that no ice nucleation occurs below the threshold ice saturation ratio $S_{0}$. Above $S_{0}$, the fraction $f_{i}$ increases exponentially according to

$f_{i}=\exp \left[a\left(S_{i}-S_{0}\right)\right]-1$.

where both $S_{0}$ and the scaling factor $a$ may depend on aerosol properties and the temperature. Fits of Eq. (3) to the experimental data, which are defined for $0<f_{i}<1$, are shown as solid lines in Figs. 7 and 8. The exponential approximations were applied to the OPC-PCS data sets of $f_{i}$ for experiment series IN02 and IN03 and the OPC-Welas data sets for IN04. The resulting fit parameters $S_{0}$ and $a$ are listed in Table 2 for all experiments with reliable data sets of $f_{i}$ and $S_{i}$. For all runs the ice nucleation was found to start at very low threshold ratios $1.0<S_{0}<1.19$. The highest values of 1.1 and 1.19 are found for runs with SD2 and AD1, respectively, at temperatures above $220 \mathrm{~K}$. For the experiments at the lowest temperatures around $197 \mathrm{~K}$ we only obtained an estimate for $S_{0}$ of 1.1 and 1.02 for ATD and SD2, respectively.

The exponential factor $a$ determines the steepness of the activation curve and therefore the formation rate of ice crystals as function of $S_{i}$. This factor scatters between 3.3 and 13.2 for all experiments with ATD. Mean values of 4.7 and 9.2 are obtained for the three runs at $223 \mathrm{~K}$ and $210 \mathrm{~K}$, respectively. The higher value at the lower temperature is consistent with the fact that also $f_{\max }$ is higher at the lower temperature (see Sect. 3.1). For the experiments with the desert dust samples, the exponential factor is somewhat smaller with values of less than 1 for experiments above $220 \mathrm{~K}$ and of 1.7 to 3.0 for experiments IN04_44 and IN03_11 with SD2, respectively. This also shows the ice activity of SD2 to increase with decreasing temperature.

We have also calculated from Eq. (3) the ice saturation $S_{8 \%}$ at which $f_{i}$ exceeded a value of 0.08 (see Table 2). In a companion paper Field et al. (2006) show, that a value of $f_{i} \approx 0.08$ separates two different ice nucleation modes, which appeared in repeated ice nucleation and evaporation cycles with the desert dust samples AD1 and SD2. For comparison with these results we have chosen the same threshold value of 0.08. Field et al. (2006) describe the characteristics of the dual mode nucleation behaviour and explain the second ice nucleation mode, which appears at $S_{i}$ between 1.35 and 1.5, either as a second deposition or a condensation type mode of

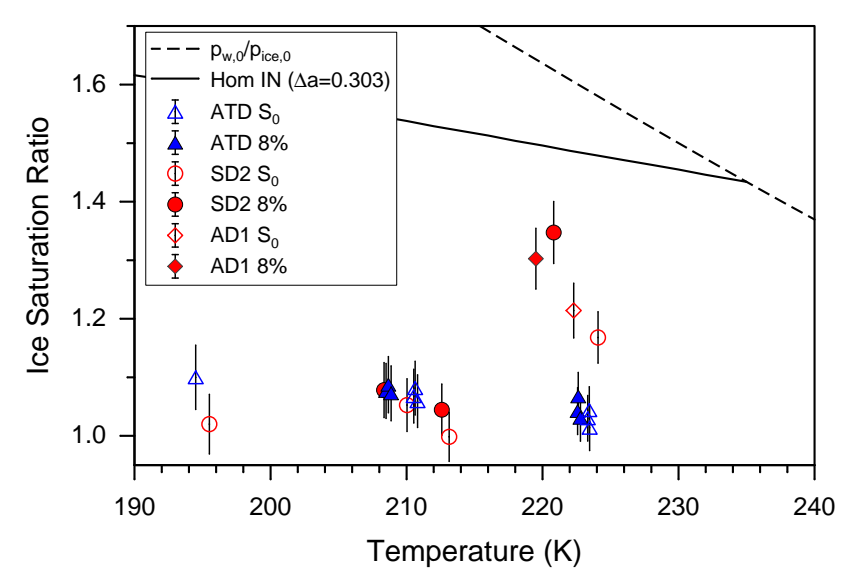

Fig. 9. Threshold ice saturation ratios for freezing onset (open symbols) and for $8 \%$ ice activated aerosol fraction. The vertical bars show the estimated uncertainty for $S_{i}$. Also shown are the ratio of the saturation pressures for pure liquid water (dashed line) and typical ice saturation ratios for the freezing of solution droplets according to Koop et al. (2000). The water vapour saturation pressures are taken from Murphy and Koop (2005).

ice nucleation. The second mode became more obvious in the subsequent expansion runs of the same dust aerosol. The parameterisation we suggest here applies only to the first deposition nucleation mode in freshly dispersed dust samples and low ice supersaturations. To avoid interference with the second nucleation mode the fit discussed here have been restricted to $S_{i}<1.35$.

Figure 9 depicts, as function of temperature, the threshold ice saturation ratios $S_{0}$ (open symbols) and $S_{8 \%}$ (closed symbols). The onset thresholds are below 1.1 for all three dust types except for the desert dust samples SD2 and AD1 at the highest temperature. Also $S_{8 \%}$ is significantly higher for the desert dusts at similar temperatures. At the lowest temperatures only the ice nucleation onset could be determined for ATD and SD2. The characteristics of ice nucleation on SD2 and AD1 dust aerosols at temperatures above $220 \mathrm{~K}$ are discussed by Field et al. (2006).

The ice nucleation efficiency of the different dust aerosols can also be expressed by the relative increase of $f_{i}$ with $S_{i}$, which is obtained from Eq. (3) as

$\frac{d f_{i}}{d S_{i}}=a \exp \left[a\left(S_{i}-S_{0}\right)\right]=a\left(f_{i}+1\right)$.

It can be seen that $d f_{i} / d S_{i}$ is initially determined by the parameter $a$ and is larger by a factor of two when $f_{i}$ approaches its maximum value of 1 . Values calculated for $f_{i}=0.08$ are listed in Table 2. The formation rate of ice crystals can be calculated from Eqs. (1) and (4) as

$\frac{d n_{\text {ice }}}{d t}=n_{p} \frac{d f_{i}}{d S_{i}} \frac{d S_{i}}{d t} \approx n_{p} a \frac{d S_{i}}{d t}$

where the approximation neglects the exponential factor in Eq. (4). This equation may be used to parameterise the ice 
formation rate by deposition nucleation in models as function of the rate of ice saturation increase above $S_{0}$, provided that the aerosol particle concentration $n_{p}$ and the respective parameters $S_{0}$ and $a$ are known. It should be noted that in the laboratory experiments reported here these parameters significantly varied with temperature and the type of dust. Ageing processes like surface coating may cause additional change. Further experiments are needed to properly assess the variation of the activation spectra for atmospheric dust particles.

\subsection{Nucleation rates}

It is difficult if not impossible to formulate a surface nucleation rate for a complex system like a mineral dust aerosol, which is composed of particles with different sizes, mineralogy, shape, and surface roughness. Nevertheless, experimental data may, if appropriate, be used to estimate nucleation rates as function of temperature, ice supersaturation, and aerosol properties. Archuleta et al. (2005) e.g. calculated, from ice nucleation measurements in a continuous flow diffusion chamber, heterogeneous surface nucleation rates $J_{s}$ on size-fractionated aluminium and iron oxide particles with diameters between 50 and $200 \mathrm{~nm}$, which were treated with sulphuric acid. As expected, $J_{s}$ was larger at larger relative humidity or water activity of the sulphuric acid and lower temperature. At temperatures between about 203 and $233 \mathrm{~K}$ and water activities between 0.79 and $0.91, J_{s}$ varied between about $10^{5}$ and $10^{7} \mathrm{~cm}^{-2} \mathrm{~s}^{-1}$. In a flow tube study with similar oxide particles but with ammonium sulphate instead of sulphuric acid treatment, Hung et al. (2003) found $J_{S}$ to be about a factor of 100 lower at temperatures around $233 \mathrm{~K}$.

To estimate an equivalent surface nucleation rate for the conditions of our experiments we first calculated the formation rate of ice crystals from Eqs. (5) and (4) for $f_{i}=0.08$ with the total particle concentration $n_{p}$ discussed in Sect. 2.5. Assuming that all particles form ice germs with the same surface nucleation rate we can calculate the effective surface nucleation rate $J_{s}$ from the ratio of the measured ice formation rate and the aerosol surface area concentration $s_{a e}$. The aerosol surface area was calculated from the size distribution parameters given in Table 1 and the initial aerosol number concentration (see Table 1) minus the $8 \%$ of particles that already acted as ice nuclei. Here we neglect the fact that the size distribution parameters of the dust aerosol should change with ongoing ice nucleation because the larger particles with larger surface areas nucleate first. From the results listed in Table 2 we get mean values of about $3 \times 10^{6}$ and $5 \times 10^{6} \mathrm{~cm}^{-2} \mathrm{~s}^{-1}$ for the runs with ATD at 223 and $210 \mathrm{~K}$, respectively. The nucleation rates are smaller by a factor of 5 to 10 for the Asian and Saharan desert dusts. As mentioned above, this difference cannot be explained by a size effect, because the different aerosols showed similar size distributions and surface area concentrations.
It is important to note that the nucleation rates estimated above only apply for the conditions of our experiments, i.e a mixture of dust particles with diameters mainly between about 0.1 and $1 \mu \mathrm{m}$ and a steady increase of $S_{i}$ at different rates given in Table 2. As already discussed in Sect. 3.1 the formation rate of ice crystals and therefore the nucleation rate approaches zero as soon as $S_{i}$ reaches its maximum value, even if a significant fraction of the dust particles have not yet formed an ice crystal.

\section{Conclusions}

In three series of AIDA cloud chamber experiments at cirrus temperatures between 196 and $223 \mathrm{~K}$ we investigated the deposition mode ice nucleation efficiency of so-called Arizona Test Dust as reference aerosol and two desert dust samples from Asia (AD1) and the Sahara (SD2). The latter two may be more typical for dust particles found in the atmosphere. The aerosols were generated by dry dispersion of the dust samples and inertial removal of particles with diameters larger than about $2 \mu \mathrm{m}$. The size distributions of the dust aerosols could be approximated by lognormal fits with mode diameters of about 0.3 to $0.5 \mu \mathrm{m}$ and geometric standard deviations of about 1.6 to 1.9. During the cloud chamber experiments, different rates of cooling and increase of ice saturation ratio where achieved by controlled pumping. In 12 experiments with different initial temperatures and aerosol number concentrations the fraction $f_{i}$ of ice particles, i.e. ice activated aerosol particles, to the total particle (aerosol plus ice) number concentration was measured as a function of the increasing ice saturation ratio.

All three mineral dust aerosol samples contained significant numbers of very efficient deposition ice nuclei. Heterogeneous ice nucleation already started at ice saturation ratios $S_{i}$ below 1.2, in most cases below 1.1. The ATD sample was most active with activated fractions of about 0.6 and 0.8 at $S_{i}<1.15$ and temperatures of 223 and $209 \mathrm{~K}$, respectively (see also Möhler et al., 2005b, and Mangold et al., 2005). The desert dust samples SD2 and AD1 showed a significantly lower fraction of deposition nuclei, about 0.25 at $223 \mathrm{~K}$ and $S_{i}<1.35$. Archuleta et al. (2005) investigated the ice nucleation of re-suspended and size segregated particles from another Asian dust sample. At $223 \mathrm{~K}$, only $1 \%$ of particles with a diameter of $0.2 \mu \mathrm{m}$ acted as ice nuclei. In the same study, smaller dust particles showed an even higher ice saturation threshold for ice nucleation on the same fraction of particles. Because in our study most particles were larger than $0.2 \mu \mathrm{m}$, the higher fraction of ice active dust particles may be explained by the larger particle sizes. However, the difference in ice activity we observed between the ATD and desert dust samples can not be explained by a size effect, because the different aerosols showed similar size distribution. The more active ATD particles even tended to be slightly smaller. Therefore, the ice nucleation activity is also influenced by 
other particle properties like surface roughness or mineralogical composition. We can only speculate whether the higher activity of ATD is due to a higher surface roughness of the milled particles or due to the different elemental and therefore also mineral composition (see Table 1).

There is evidence that for a given aerosol sample and initial temperature the ice activation spectrum, i.e. the relation between $f_{i}$ and $S_{i}$, is almost independent of the cooling rate and the total aerosol number concentration. Furthermore, the formation of new ice particles is always correlated with an increase of $S_{i}$. The ice number fraction remains almost constant after $S_{i}$ reached its peak value. This may be explained by a given distribution of surface sites for deposition nucleation as function of $S_{i}$, which are activated almost immediately after the respective critical ice saturation ratios are exceeded. A narrow distribution results in a large value and a broad distribution in a low value of $d f_{i} / d S_{i}$. Similar to the parameterisation suggested by Meyers et al. (1992) to predict the number of heterogeneous ice nuclei at higher temperatures, we suggest an exponential equation as function of $S_{i}$ to calculate the fraction of mineral particles acting as deposition nuclei. Our limited data set already shows that both the onset ice saturation $S_{0}$ and the exponential factor $a$, which mainly determines the ice particle formation rate, depend on temperature and the type of the dust aerosol (see Table 2).

Two series of three subsequent ice activation and evaporation cycles with ATD at initial temperatures of 223 and $210 \mathrm{~K}$ showed no significant change in the ice nucleation activity. This indicates that the phenomenon of preactivation noted by Roberts and Hallett (1968) does not apply to ATD particles under the conditions of our experiments. For the desert dust samples a second ice nucleation mode appeared at $S_{i}$ between 1.35 and 1.5. The characteristics of this dual mode ice nucleation, which became more obvious in subsequent expansion runs of the same desert dust aerosol, are discussed in more detail in a companion paper (Field et al., 2006).

Initial surface nucleation rates of $3 \times 10^{6}, 2 \times 10^{5}$, and $5 \times 10^{5} \mathrm{~cm}^{-2} \mathrm{~s}^{-1}$, were determined at about $223 \mathrm{~K}$ for ATD, $\mathrm{SD} 2$, and $\mathrm{AD} 1$, respectively. However, the formation rate of ice crystals and therefore the nucleation rate dropped to markedly lower values as soon as $S_{i}$ reached its maximum value, even if a significant fraction of the dust particles have not yet formed an ice crystal. From this we conclude that the concept of surface nucleation rates may not be feasible to predict ice formation by deposition nucleation in complex mineral dust aerosols, at least under the conditions of our experiments, which are similar to cloud expansion at updraft velocities of about 0.5 to $2 \mathrm{~m} / \mathrm{s}$. Our experimental results indicate that a parameterisation of the ice active aerosol particle fraction as function of only the ice saturation ratio may be more appropriate for atmospheric models to calculate the ice formation rate. Further experiments and process modelling studies are needed to assess the influence of temperature and particle properties on the respective ice activation spectra of mineral dust aerosols.
Acknowledgements. Continuous support by the AIDA staff members R. Buschbacher, T. Chudy, E. Kranz, G. Scheurig, and S. Vogt is gratefully acknowledged. We thank L. Schütz from the Universtiy Mainz, Germany, for providing the dust sample from the Takla Makan desert in Asia, and K. Megahed for collecting the Saharan dust sample. We also thank C. Adelhelm from the Institute of Material Research (IMF I) of Forschungszentrum Karlsruhe for XRF analysis of mineral dust samples. The first author is grateful to the National Center for Atmospheric Research (NCAR) in Boulder, Colorado, for financial support of a stay as visiting scientist, which was partially used for data analysis and preparation of this manuscript. This work contributes to the HGF (Hermann-von-Helmholtz-Gemeinschaft Deutscher Forschungszentren) project Particles and Cirrus Clouds (PAZI-II). Part of this work was funded within the European Union Integrated Project SCOUT-O3.

Edited by: T. Koop

\section{References}

Archuleta, C. M., DeMott, P. J., and Kreidenweis, S. M.: Ice nucleation by surrogates for atmospheric mineral dust and mineral dust/sulfate particles at cirrus temperatures, Atmos. Chem. Phys., 5, 2617-2634, 2005, http://www.atmos-chem-phys.net/5/2617/2005/.

Bailey, M. and Hallett, J.: Nucleation effects on the habit of vapour grown ice crystals from -18 to $-42^{\circ} \mathrm{C}$, Quart. J. Royal Meteorol. Soc., 128, 1461-1483, 2002.

Benz, S., Megahed, K., Möhler, O., Saathoff, H., Wagner, R., and Schurath, U.: T-dependent rate measurements of homogeneous ice nucleation in cloud droplets using a large atmospheric simulation chamber, J. Photochem. Photobiol. A, 176, 208-217, doi:10.1016/j.jphotochem.2005.08.026, 2005.

Chen, Y. L., Kreidenweis, S. M., McInnes, L. M., Rogers, D. C., and DeMott, P. J.: Single particle analyses of ice nucleating aerosols in the upper troposphere and lower stratosphere, Geophys. Res. Lett., 25, 1391-1394, 1998.

Cziczo, D. J., Murphy, D. M., Hudson, P. K., and Thomson, D. S.: Single particle measurements of the chemical composition of cirrus ice residue during CRYSTAL-FACE, J. Geophys. Res., 109, D04 201, doi:10.1029/2003JD004 032, 2004.

Dahneke, B.: Simple Kinetic Theory of Brownian Diffusion in Vapors and Aerosols, in: Theory of Dispersed Multiphase Flow, edited by: Meyer, R. E., Academic Press, New York, pp. 97133, 1983.

DeMott, P. J., Rogers, D. C., Kreidenweis, S. M., Chen, Y. L., Twohy, C. H., Baumgardner, D., Heymsfield, A. J., and Chan, K. R.: The role of heterogeneous freezing nucleation in upper tropospheric clouds: Inferences from SUCCESS, Geophys. Res. Lett., 25, 1387-1390, 1998.

DeMott, P. J., Sassen, K., Poellot, M. R., Baumgardner, D., Rogers, D. C., Brooks, S. D., Prenni, A. J., and Kreidenweis, S. M.: African dust aerosols as atmospheric ice nuclei, Geophys. Res. Lett., 30(14), 1732, doi:10.1029/2003GL017 410, 2003.

Diehl, K. and Wurzler, S.: Heterogeneous drop freezing in the immersion mode: Model calculations considering soluble and insoluble particles in the drops, J. Atmos. Sci., 61, 2063-2072, 2004. 
Ebert, V., Teichert, H., Giesemann, C., Saathoff, H., and Schurath, U.: Fibre-coupled in-situ laser absorption spectrometer for the selective detection of water vapour traces down to the ppb-level, Tech. Mess., 72, 23-30, 2005.

Field, P. R., Cotton, R. J., Noone, K., Glantz, P., Kaye, P. H., Hirst, E., Greenaway, R. S., Jost, C., Gabriel, R., Reiner, T., Andreae, M., Saunders, C. P. R., Archer, A., Choularton, T., Smith, M., Brooks, B., Hoell, C., Bandy, B., Johnson, D., and Heymsfield, A.: Ice nucleation in orographic wave clouds: Measurements made during INTACC, Quart. J. Royal Meteorol. Soc., 127, 1493-1512, 2001.

Field, P. R., Möhler, O., Connolly, P., Krämer, M., Cotton, R. J., Heymsfield, A. J., and Schnaiter, M.: Some ice nucleation characteristics of Asian and Saharan desert dust, Atmos. Chem. Phys., 6, 2991-3006, 2006,

http://www.atmos-chem-phys.net/6/2991/2006/.

Fletcher, N. H.: Physics of rain clouds, Cambridge University Press, 1962.

Gustafsson, R. J., Orlov, A., Badger, C. L., Griffiths, P. T., Cox, R. A., and Lambert, R. M.: A comprehensive evaluation of water uptake on atmospherically relaevant mineral surfaces: DRIFT spectroscopy, thermogravimetric analysis and aerosol growth measurements, Atmos. Chem. Phys., 5, 3415-3421, 2005, http://www.atmos-chem-phys.net/5/3415/2005/.

Haag, W., Kärcher, B., Ström, J., Minikin, A., Lohmann, U., Ovarlez, J., and Stohl, A.: Freezing thresholds and cirrus cloud formation mechanisms inferred from in situ measurements of relative humidity, Atmos. Chem. Phys., 3, 1791-1806, 2003,

http://www.atmos-chem-phys.net/3/1791/2003/.

Heintzenberg, J., Okada, K., and Ström, J.: On the composition of non-volatile material in upper tropospheric aerosols and cirrus crystals, Atmos. Res., 41, 81-88, 1996.

Heymsfield, A. J. and Miloshevich, L. M.: Homogeneous Ice Nucleation and Supercooled Liquid Water in Orographic Wave Clouds, J. Atmos. Sci., 50, 2335-2353, 1993.

Hirst, E., Kaye, P. H., Greenaway, R. S., Field, P., and Johnson, D. W.: Discrimination of micrometre-sized ice and supercooled droplets in mixed-phase cloud, Atmos. Environ., 35, 3347, 2001.

Hung, H.-M., Malinowski, S. T., and Martin, S. T.: Kinetics of heterogeneous ice nucleation on the surfaces of mineral dust cores inserted into aqueous ammonium sulfate particles, J. Phys. Chem. A, 107, 1296-1306, 2003.

Jensen, E. J., Toon, O. B., Tabazadeh, A., Sachse, G. W., Anderson, B. E., Chan, K. R., Twohy, C. W., Gandrud, B., Aulenbach, S. M., Heymsfield, A., Hallett, J., and Gary, B.: Ice nucleation processes in upper tropospheric wave-clouds observed during SUCCESS, Geophys. Res. Lett., 25, 1363-1366, 1998.

Kärcher, B. and Lohmann, U.: A Parameterization of cirrus cloud formation: Homogeneous freezing including effects of aerosol size, J. Geophys. Res., 107, 4698, doi:10.1029/2001JD001 429, 2002.

Kärcher, B. and Lohmann, U.: A parameterization of cirrus cloud formation: Heterogeneous freezing, J. Geophys. Res., 108, 4402, doi:10.1029/2002JD003 220, 2003.

Koop, T., Luo, B. P., Tsias, A., and Peter, T.: Water activity as the determinant for homogeneous ice nucleation in aqueous solutions, Nature, 406, 611-614, 2000.

Lohmann, U., Kärcher, B., and Hendricks, J.: Sensitivity studies of cirrus clouds formed by heterogeneous freezing in the ECHAM GCM, J. Geophys. Res., 109, D16204, doi:10.1029/2003JD004 443, 2004.

Lynch, D. K., Sassen, K., Starr, D. O., and Stephens, G. (Eds.): Cirrus, Oxford University Press, 2002.

Mangold, A., Wagner, R., Saathoff, H., Schurath, U., Giesemann, C., Ebert, V., Krämer, M., and Möhler, O.: Experimental investigation of ice nucleation by different types of aerosols in the aerosol chamber AIDA: implications to microphysics of cirrus clouds, Meteorol. Z., 14, 485-497, 2005.

Meyers, M. P., Demott, P. J., and Cotton, W. R.: New Primary Ice-Nucleation Parameterizations in an Explicit Cloud Model, J. Appl. Meteorol., 31, 708-721, 1992.

Mishchenko, M. I. and Travis, L. D.: Capabilities and limitations of a current FORTRAN implementation of the T-matrix method for randomly oriented, rotationally symmetric scatterers, J. Quant. Spectroscop. Radiat. Transfer, 60, 309-324, 1998.

Möhler, O., Stetzer, O., Schaefers, S., Linke, C., Schnaiter, M., Tiede, R., Saathoff, H., Krämer, M., Mangold, A., Budz, P., Zink, P., Schreiner, J., Mauersberger, K., Haag, W., Kärcher, B., and Schurath, U.: Experimental investigation of homogeneous freezing of sulphuric acid particles in the aerosol chamber AIDA, Atmos. Chem. Phys., 3, 211-223, 2003, http://www.atmos-chem-phys.net/3/211/2003/.

Möhler, O., Büttner, S., Linke, C., Schnaiter, M., Saathoff, H., Stetzer, O., Wagner, R., Krämer, M., Mangold, A., Ebert, V., and Schurath, U.: Effect of sulphuric acid coating on heterogeneous ice nucleation by soot aerosol particles, J. Geophys. Res., 110, D11 210, doi:10.1029/2004JD005 169, 2005a.

Möhler, O., Linke, C., Saathoff, H., Schnaiter, M., Wagner, R., Mangold, A., Krämer, M., and Schurath, U.: Ice nucleation on flame soot aerosol of different organic carbon content, Meteorol. Z., 14, 477-484, 2005b.

Murphy, D. M. and Koop, T.: Review of the vapour pressures of ice and supercooled water for atmospheric applications, Quart. J. Royal Met. Soc., 131, 1539-1565, 2005.

Pruppacher, H. R. and Klett, J. D.: Microphysics of clouds and precipitation, Kluwer Academic Publishers, Dordrecht, The Netherlands, 1997.

Roberts, P. and Hallett, J.: A laboratory study of the ice nucleating properties of some mineral particulates, Quart. J. Royal Meteorol. Soc., 94, 25-34, 1968.

Sassen, K. and Dodd, G. C.: Homogeneous Nucleation Rate for Highly Supercooled Cirrus Cloud Droplets, J. Atmos. Sci., 45, 1357-1369, 1988.

Sassen, K., DeMott, P. J., Prospero, J. M., and Poellot, M. R.: Saharan dust storms and indirect aerosol effects on clouds: CRYSTAL-FACE results, Geophys. Res. Lett., 30, 1633, doi:10.1029/2003GL017 371, 2003.

Seifert, M., Strom, J., Krejci, R., Minikin, A., Petzold, A., Gayet, J. F., Schumann, U., and Ovarlez, J.: In-situ observations of aerosol particles remaining from evaporated cirrus crystals: Comparing clean and polluted air masses, Atmos. Chem. Phys., 3, 1037-1049, 2003, http://www.atmos-chem-phys.net/3/1037/2003/.

Seifert, M., Tiede, R., Schnaiter, M., Linke, C., Möhler, O., Schurath, U., and Ström, J.: Operation and performance of a differential mobility particle sizer and a TSI 3010 condensation particle counter at stratospheric temperatures and pressures, J. Aerosol 
Sci., 35, 981-993, 2004.

Ström, J., Seifert, M., Kärcher, B., Ovarlez, J., Minikin, A., Gayet, J. F., Krejci, R., Petzold, A., Auriol, F., Haag, W., Busen, R., Schumann, U., and Hansson, H. C.: Cirrus cloud occurrence as function of ambient relative humidity: a comparison of observations obtained during the INCA experiment, Atmos. Chem. Phys., 3, 1807-1816, 2003, http://www.atmos-chem-phys.net/3/1807/2003/.

Targino, A. C., Krejci, R., Noone, K. J., and Glantz, P.: Single particle analysis of ice crystal residuals observed in orographic wave clouds over Scandinavia during INTACC experiment, Atmos. Chem. Phys., 6, 1977-1990, 2006, http://www.atmos-chem-phys.net/6/1977/2006/.

Twohy, C. H. and Poellot, M. R.: Chemical characteristics of ice residual nuclei in anvil cirrus clouds: evidence for homogeneous and heterogeneous ice formation, Atmos. Chem. Phys., 5, 22892297, 2005, http://www.atmos-chem-phys.net/5/2289/2005/.

Vali, G.: Nucleation Terminology, Bull. Am. Meteorol. Soc., 66, 1426-1427, 1985.
Wagner, R., Benz, S., Möhler, O., Saathoff, H., Schnaiter, M., and Schurath, U.: Mid-infrared extinction spectra and optical constants of supercooled water droplets, J. Phys. Chem. A, 109, 7099-7112, 2005.

Wagner, R., Benz, S., Möhler, O., Saathoff, H., and Schurath, U.: Probing ice clouds by broadband mid-infrared extinction spectroscopy: case studies from ice nucleation experiments in the AIDA aerosol and cloud chamber, Atmos. Chem. Phys. Discuss., 6, 5711-5771, 2006, http://www.atmos-chem-phys-discuss.net/6/5711/2006/.

Zöger, M., Afchine, A., Eicke, N., Gerhards, M.-T., Klein, E., McKenna, D., Mörschel, U., Schmidt, U., Tan, V., Tuitjer, F., Woyke, T., and Schiller, C.: Fast in situ stratospheric hygrometers: A new family of balloon-borne and airborne Lyman a photofragment fluorescence hygrometers, J. Geophys. Res., 104(D1), 1807-1816, 1999.

Zuberi, B., Bertram, A. K., Cassa, C. A., Molina, L. T., and Molina, M. J.: Heterogeneous nucleation of ice in $\left(\mathrm{NH}_{4}\right)_{2} \mathrm{SO}_{4}-\mathrm{H}_{2} \mathrm{O}$ particles with mineral dust immersions, Geophys. Res. Lett., 29(10), 1504, doi:10.1029/2001GL014 289, 2002. 